\title{
Effect of glucocorticoid therapy on adrenal function in children with acute lymphoblastic leukemia
}

\author{
Gita Widyapuri, Djajadiman Gatot, Aman Bakti Pulungan, Badriul Hegar
}

\begin{abstract}
Background Glucocorticoids play an important role in the treatment of acute lymphoblastic leukemia (ALL), but can cause side effects such as suppression of the hypothalamic-pituitaryadrenal (HPA) axis. Suppression of the HPA axis causes adrenal insufficiency, disturbs the cortisol response to stress, and may be a cause of morbidity and mortality in children with ALL.

Objective To evaluate adrenal function in children with ALL after induction chemotherapy with high dose glucocorticoids.

Methods The adrenal function of 20 children with ALL was evaluated using a standard dose $(250 \mu \mathrm{g})$ adrenocorticotropin hormone (ACTH) test performed before and after a 6 week of treatment with glucocorticoids induction phase chemotherapy, which was followed by a week period tapering off. Adrenal insuffiency was defined as blood cortisol level of $<18 \mu \mathrm{g} / \mathrm{dL}$

Results Adrenal insufficiency was found in 14/20 subjects after the induction phase followed by a week period of tapering off. Median cortisol levels pre-and post-stimulation before induction phase were 14.72 (range 2.01 - 46.1) $\mu \mathrm{g} / \mathrm{dL}$ and 29.29 (range 21.65 $-55.15) \mu \mathrm{g} / \mathrm{dL}$, respectively. Median cortisol levels pre- and poststimulation after induction phase were 5.87 (range 0.2 - 20.53) $\mu \mathrm{g} / \mathrm{dL}$ and 10.49 (range $0.33-28.69$ ) $\mu \mathrm{g} / \mathrm{dL}$, respectively. Clinical signs and symptoms did not differ between those with and without adrenal insufficiency.

Conclusion Of 20 children with ALL, 14 develop adrenal insufficiency after a 6-week induction therapy with glucocorticoids and followed by a week period of tapering off. No specific clinical signs and symptoms are identified to be related to the adrenal insufficiency. [Paediatr Indones. 2014;54:15-21.].
\end{abstract}

Keywords: acute lymphoblastic leukemia, children, glucocorticoids
A

cute lymphoblastic leukemia is the most common leukemia in children less than 15 years of age and represents $75-80 \%$ of all leukemia cases. ${ }^{1}$ The five-year event-free survival rate for ALL in children is $70-83 \%$ in developed countries with an $80 \%$ cure rate. However, in poor and developing countries the cure rate is reported to be less than $35 \% .^{2-7}$ Factors that play a role in the therapy failure in these countries are late diagnosis, high rates of relapse, drug withdrawal, death due to drug side effects, lack of supportive therapy, and the presence of comorbidities. Approximately 1-3\% of patients die during the induction phase of post-remission chemotherapy or due to complications related to chemotherapy. 8,9

High-dose glucocorticoids play an important role in ALL treatment, but can cause disturbances in the HPA axis, leading to atrophy of the adrenal cortex and resulting in secondary adrenal insufficiency. Suppression of the HPA axis causes adrenal insufficiency, disturbs the cortisol response to stress, and may be a cause of morbidity and mortality in children with

From the Department of Child Health, University of Indonesia Medical School, Jakarta, Indonesia.

Reprint requests to: Gita Widyapuri, Department of Child Health, University of Indonesia Medical School, Cipto Mangunkusumo Hospital. Jl. Diponegoro no.71 Jakarta 10430, Indonesia. Tel. +62-21-3919016. E-mail: gwidyapuri@gmail.com. 
ALL. ${ }^{10-12}$ Adrenal insufficiency should be diagnosed early to avoid the risk of acute adrenal crisis. Currently there is little data on adrenal gland function after the administration of high-dose glucocorticoids in Indonesian children with ALL treated using the 2006 Indonesian Chemotherapy ALL Protocol.

\section{Methods}

From January to October 2012, 31 children with newly diagnosed ALL were consecutively enrolled in the study. These patients came from several hospitals in Jakarta; those were Cipto Mangunkusumo Hospital, Harapan Kita Mother and Child Hospital, and Fatmawati Hospital. Acute lymphoblastic leukemia (ALL) was determined based on bone marrow aspiration and/or immunophenotyping. The study protocol was approved by the Regional Ethics Committee and informed consent was obtained. Eleven children were excluded for the following reasons: refusal to receive chemotherapy ( 2 children), not passing the initial adrenal function test (1 child), failure to complete the induction phase of chemotherapy until the end of the study (1 child), and death before finishing the induction phase (7 children). Thus, this study series consisted of 20 children. None had received glucocorticoid therapy for other disorders. Nine had standard-risk (SR) of ALL and 11 had high-risk (HR) of ALL.

The children were treated with risk-adapted chemotherapy according to the 2006 Indonesian Chemotherapy ALL Protocol. All children received a 5 -week course of prednisone $\left(40 \mathrm{mg} / \mathrm{m}^{2} /\right.$ day $)$ or dexamethasone $\left(4 \mathrm{mg} / \mathrm{m}^{2} /\right.$ day for $\mathrm{SR}, 6 \mathrm{mg} / \mathrm{m}^{2} /$ day for HR) as part of induction therapy, with gradual tapering over a week period. Weekly vincristine (1.5 $\mathrm{mg} / \mathrm{m}^{2} \times 6$ ), four doses of intrathecal methotrexate, $\mathrm{L}$-asparaginase (6 doses of $6000 \mathrm{U} / \mathrm{m}^{2}$ in 2 weeks), and weekly daunorubicine $\left(30 \mathrm{mg} / \mathrm{m}^{2} \times 4\right)$ were administered concomitantly. We obtained clinical and laboratory findings from all children before and after the induction phase.

Adrenal function tests were conducted before the first dose of glucocorticoids and the last day of tapering off period. Adrenal function was assessed by an ACTH stimulation test, performed between 7:00-8:00 AM, with all blood specimens drawn from a peripheral vein. Blood was collected before (baseline cortisol, $\mathrm{t}_{0}$ ) administration of $250 \mu \mathrm{g}$ synthetic ACTH (Synacten ${ }^{\circledR}$ Depot; Defiante Farmaceutica, S.A.) and 30 min after for determination of cortisol levels (ACTHstimulated cortisol, $\left.\mathrm{t}_{30-60}\right)$. Stimulated cortisol levels greater than $18 \mu \mathrm{g} / \mathrm{dL}$ after $30 \mathrm{~min}$ were considered to be a normal response. Serum concentrations of cortisol were determined by chemiluminescence with a detection limit of $0.2 \mu \mathrm{g} / \mathrm{dL}$. The intra-assay and inter-assay coefficients of variation were $10 \%$ with cortisol levels of $1-50 \mu \mathrm{g} / \mathrm{dL}$.

Wilcoxon test was used to assess differences between cortisol levels before and after chemotherapy induction. Unpaired t-test and Mann-Whitney test were used to assess possible differences between patients showing normal or insufficient adrenal function. $\mathrm{P}$ values $<0.05$ were considered to be statistically significant. Data analyses were performed using SPSS version 17.

\section{Results}

Thirty-one children with newly-diagnosed ALL were included in the study, but only 20 patients (14 boys, 6

Table 1. Characteristics of subjects

\begin{tabular}{ll}
\hline Characteristics & $\mathrm{n}=20$ \\
\hline Mean age, years (SD) & $7.2(3.5)$ \\
Gender & \\
$\quad$ Male & 14 \\
$\quad$ Female & 6 \\
Bone marrow aspiration & \\
$\quad$ L1 & 17 \\
L2 & 3 \\
$\quad$ Not done & 0 \\
Immunophenotyping & \\
$\quad$ B lineage & 12 \\
$\quad$ T lineage & 2 \\
$\quad$ Other & 1 \\
$\quad$ Not done & 5 \\
Risk group & \\
$\quad$ Standard & 9 \\
High & 11 \\
Glucocorticoid used & \\
$\quad$ Dexamethasone & 17 \\
Prednisone & 3 \\
Hemoglobin, g/dL (SD) & $7.4(2.3)$ \\
Median leukocytes, / $\mu \mathrm{L}$ (range) & $30.245(1.300-226.000)$ \\
Median platelets count, / $\mathrm{LL}$ (range) & $38.848(12.268-65.428)$ \\
\hline
\end{tabular}


Gita Widyapuri et al: Adrenal function in children with acute lymphoblastic leukimia

Table 2. Adrenal function tests before and after induction chemotherapy

\begin{tabular}{|c|c|c|c|c|c|c|c|}
\hline \multirow{2}{*}{$\begin{array}{l}\text { Subject } \\
\text { No. }\end{array}$} & \multirow{2}{*}{$\begin{array}{l}\text { Age, } \\
\text { years }\end{array}$} & \multicolumn{3}{|c|}{ Before induction } & \multicolumn{3}{|c|}{ After induction } \\
\hline & & $\begin{array}{c}t_{0} \\
\mu \mathrm{g} / \mathrm{dL}\end{array}$ & $\begin{array}{r}t_{30-60} \\
\mu \mathrm{g} / \mathrm{dL}\end{array}$ & $\begin{array}{l}\text { Adrenal } \\
\text { function }\end{array}$ & $\begin{array}{c}t_{0} \\
\mu g / d L\end{array}$ & $\begin{array}{r}t_{30-60} \\
\mu \mathrm{g} / \mathrm{dL}\end{array}$ & $\begin{array}{l}\text { Adrenal } \\
\text { function }\end{array}$ \\
\hline 1 & 3 & 12.77 & 29.04 & normal & 1.61 & 3.15 & insufficient \\
\hline 2 & 9 & 15.64 & 31.73 & normal & 8.82 & 22.35 & normal \\
\hline 3 & 6 & 15.81 & 34.17 & normal & 11.18 & 27.47 & normal \\
\hline 4 & 5 & 2.01 & 21.78 & normal & 8.63 & 13.80 & insufficient \\
\hline 5 & 6 & 9.99 & 30.22 & normal & 0.56 & 1.53 & insufficient \\
\hline 6 & 7 & 19.86 & 29.94 & normal & 5.17 & 13.76 & insufficient \\
\hline 7 & 4 & 13.41 & 26.39 & normal & 7.30 & 8.85 & insufficient \\
\hline 8 & 10 & 18.39 & 29.54 & normal & 4.17 & 7.01 & insufficient \\
\hline 9 & 13 & 13.71 & 27.20 & normal & 7.08 & 12.14 & insufficient \\
\hline 10 & 3 & 15.50 & 30.04 & normal & 6.57 & 15.11 & insufficient \\
\hline 11 & 9 & 13.94 & 32.86 & normal & 7.22 & 21.74 & normal \\
\hline 12 & 9 & 20.94 & 21.65 & normal & 0.52 & 7.01 & insufficient \\
\hline 13 & 14 & 11.77 & 24.90 & normal & 8.04 & 22.03 & normal \\
\hline 14 & 10 & 46.10 & 26.19 & normal & 13.76 & 28.69 & normal \\
\hline 15 & 12 & 11.93 & 31.13 & normal & 20.53 & 27.61 & normal \\
\hline 16 & 7 & 12.60 & 24.16 & normal & 0.20 & 0.33 & insufficient \\
\hline 17 & 3 & 22.69 & 55.12 & normal & 2.72 & 3.80 & insufficient \\
\hline 18 & 3 & 12.77 & 22.33 & normal & 2.06 & 8.52 & insufficient \\
\hline 19 & 3 & 15.64 & 33.39 & normal & 0.46 & 3.75 & insufficient \\
\hline 20 & 10 & 15.81 & 23.02 & normal & 3.18 & 8.24 & insufficient \\
\hline
\end{tabular}

$t_{0}=$ baseline cortisol before ACTH test

$\mathrm{t}_{30-60}=$ stimulated cortisol after ACTH test

Table 3. Cortisol levels before and after induction chemotherapy

\begin{tabular}{llcl}
\hline Variables & Before induction & After induction & $P$ value* \\
\hline Baseline cortisol $\left(t_{0}\right)$ & $14.72(2.01-46.1)$ & $5.87(0.2-20.53)$ & $<0.001$ \\
ACTH-stimulated cortisol $\left(t_{30-60}\right)$ & $29.29(21.65-55.15)$ & $10.49(0.33-28.69)$ & $<0.001$ \\
\hline
\end{tabular}

Cortisol levels measured in $\mu \mathrm{g} / \mathrm{dL}$ and presented in median (minimum-maximum)

*Wilcoxon test

girls), aged 3-14 years with a mean age of 7.2 (SD 3.5) years, completed the induction phase of chemotherapy and were evaluated in the study. Characteristics of the subjects can be seen in Table 1 .

All 20 children had a normal cortisol response to standard dose ACTH stimulation test before starting the 5-week glucocorticoid therapy. Results of ACTH testing at 1 week after completion of induction chemotherapy revealed adrenal insufficiency in 14 out of the 20 children (Table 2).

Statistical analysis revealed significant differences in both baseline cortisol levels and ACTHstimulated cortisol levels before induction chemotherapy compared to 1 week after completing therapy (Table 3).

After completion of induction chemotherapy and a week period of tapering off, all patients were examined for clinical signs of adrenal insufficiency such as malaise, anorexia, nausea, abdominal pain, fever, weight loss, and blood pressure. Laboratory results, including the post-induction ACTH stimulation test, are shown in Table 4. No subjects showed any signs of acute adrenal crisis.

\section{Discussion}

The level of morning serum cortisol provides information about basal adrenocortical activity, but does not reflect the ability of the HPA axis to react to stress. Such ability can only be evaluated by determining the rise in serum cortisol in response to stimulation, such as to ACTH. The $250 \mu \mathrm{g}$ ACTH stimulation test is the most commonly used test to diagnose adrenal insufficiency. Peak cortisol levels post-ACTH test $250 \mu \mathrm{g}$ correlates with the gold 
Gita Widyapuri et al: Adrenal function in children with acute lymphoblastic leukimia

Table 4. Clinical and laboratory characteristics of subjects with and without adrenal insufficiency

\begin{tabular}{|c|c|c|c|}
\hline \multirow[b]{2}{*}{ Variables } & \multicolumn{2}{|c|}{ Adrenal insufficiency } & \multirow[b]{2}{*}{$P$ value } \\
\hline & $\begin{array}{l}\text { Yes } \\
n=14\end{array}$ & $\begin{array}{l}\text { No } \\
n=6\end{array}$ & \\
\hline Age, years (SD) & $6(3.2)$ & $10(2.7)$ & $0.018^{*}$ \\
\hline \multicolumn{4}{|l|}{ Gender, } \\
\hline Male & 11 & 3 & \multirow[t]{2}{*}{$0.005^{* \star}$} \\
\hline Female & 3 & 3 & \\
\hline \multicolumn{4}{|l|}{ Risk group } \\
\hline Standard & 6 & 3 & \multirow[t]{2}{*}{$1.000^{* *}$} \\
\hline High & 8 & 3 & \\
\hline \multicolumn{4}{|l|}{ Glucocorticoids } \\
\hline Dexamethasone & 12 & 5 & \multirow[t]{2}{*}{$1.000^{* *}$} \\
\hline Prednisone & 2 & 1 & \\
\hline Fatigue & 1 & 5 & $0.020^{* *}$ \\
\hline Anorexia & 7 & 4 & $0.640^{* *}$ \\
\hline Nausea & 1 & 3 & $0.060^{* *}$ \\
\hline Vomiting & 0 & 1 & $0.300^{* *}$ \\
\hline Abdominal pain & 1 & 0 & $1.000^{* *}$ \\
\hline Fever & 2 & 3 & $0.130^{* *}$ \\
\hline Weight loss & 2 & 1 & $1.000^{* *}$ \\
\hline Weight gain (SD), kg & $3.4(2.3)$ & $3.8(2.2)$ & $0.759^{\star}$ \\
\hline \multicolumn{4}{|l|}{ Blood pressure } \\
\hline Hypotension & 0 & 0 & \multirow[t]{5}{*}{$1.000^{* *}$} \\
\hline Normal & 13 & 6 & \\
\hline Pre-hypertension & 0 & 0 & \\
\hline Stage 1 hypertension & 1 & 0 & \\
\hline Stage 2 hypertension & 0 & 0 & \\
\hline Mean hemoglobin, g/dL (SD) & $11.6(0.98)$ & $9.7(1.41)$ & $0.003^{*}$ \\
\hline Median leukocytes, $/ \mu \mathrm{L}$ (range) & $7,800(2,020-105,270)$ & $2,395(677-6,720)$ & $0.007^{* \star \star}$ \\
\hline Platelets count, / $/ \mathrm{L}$ (SD) & $292,500(108,160)$ & $164,031(153,155)$ & $0.045^{\star}$ \\
\hline Glucose, mg/dL (SD) & $83.7(11.6)$ & $129.8(97.8)$ & $0.300^{*}$ \\
\hline $\mathrm{t}_{0}$ pre-chemotherapy, $\mu \mathrm{g} / \mathrm{dL}(\mathrm{SD})$ & $16.46(10.00)$ & $18.51(5.67)$ & $0.647^{\star}$ \\
\hline$t_{30-60}$ pre-chemotherapy, $\mu \mathrm{g} / \mathrm{dL}$ (SD) & $28.84(8.43)$ & $30.16(3.74)$ & $0.720^{*}$ \\
\hline$t_{0}$ post-chemotherapy, $\mu \mathrm{g} / \mathrm{dL}(\mathrm{SD})$ & $3.58(2.91)$ & $11.59(4.98)$ & $0.000^{*}$ \\
\hline$t_{30-60}$ post-chemotherapy, $\mu \mathrm{g} / \mathrm{dL}$ (SD) & $7.64(4.77)$ & $24.98(3.25)$ & $0.000^{*}$ \\
\hline
\end{tabular}

standard insulin tolerance test (ITT), as it has a good specificity, however, its sensitivity is uncertain. 12-14 Since the ITT is inherently dangerous and there are technical difficulties in performing the low-dose ACTH test, the standard-dose ACTH test was chosen for this study.

Fourteen out of 20 of our patients had adrenal insufficiency 1 week after cessation of glucocorticoid induction therapy, using the standard $250 \mu \mathrm{g}$ ACTH stimulation test with a cut-off value of poststimulation cortisol $<18 \mu \mathrm{g} / \mathrm{dL}$. Based on this criteria, the prevalence of adrenal insufficiency in this study was still in the incidence range previously reported, i.e., $\quad 30-70 \%$ for the ACTH stimulation test using $250 \mu \mathrm{g}$ and $17-46 \%$ in studies using the $1 \mu \mathrm{g}$ ACTH stimulation test. ${ }^{15-19}$ Interpretation and comparison of results from various studies are difficult due to variations in the sample population, research methods (timing and type of ACTH stimulation test), subjects' age, as well as type and duration of glucocorticoid administration.

Petersen et al. reported adrenal insufficiency in 7 of 10 subjects at 1 week after cessation of $60 \mathrm{mg} /$ $\mathrm{m}^{2} /$ day prednisolone for 5 weeks and a 9-day period of tapering off. ${ }^{19}$ In contrast, glucocorticoids given to the subjects of our study was largely dexamethasone 
at $6 \mathrm{mg} / \mathrm{m}^{2} /$ day. When calculating equivalent doses of glucocorticoids, a dose of $6 \mathrm{mg} / \mathrm{m}^{2} /$ day dexamethasone is less than $60 \mathrm{mg} / \mathrm{m}^{2} /$ day prednisolone given by Petersen et al. ${ }^{19}$ Furthermore, Petersen et al. ${ }^{19}$ did not perform an ACTH stimulation test prior to chemotherapy, so their subjects' baseline adrenal gland function was not known. All study subjects were given $10 \mathrm{mg} / \mathrm{m}^{2} /$ day hydrocortisone to prevent adrenal insufficiency which may have contributed to the results. ${ }^{19}$

In a study of 10 patients with ALL by Felner et al., adrenal insufficiency was present in all patients after discontinuation of $6 \mathrm{mg} / \mathrm{m}^{2} /$ day dexamethasone for 4 weeks without a tapering off period. ${ }^{18}$ Adrenal function remained impaired in 3/10 subjects after 4 weeks of dexamethasone discontinuation and all returned to normal after 8 weeks of dexamethasone discontinuation. ${ }^{18}$

To date, there is no consensus on the cortisol level that describes an adequate adrenal response to stress or indicates adrenal insufficiency. In our study, we found a significant decrease in median cortisol levels pre- and post-test, before and after chemotherapy (Table 3 ). However, the median pretest cortisol $\left(\mathrm{t}_{0}\right)$ after chemotherapy $[5.87$ (range 0.220.53) $\mathrm{mg} / \mathrm{dL}$ ] was higher than the median pre-test cortisol $\left(\mathrm{t}_{0}\right)$ obtained by Cunha et al. who reported $\mathrm{a} \mathrm{t}_{0}$ of $2.4(0.9-11.2) \mathrm{mg} / \mathrm{dL} 48$ hours after a 10 -day tapering off from $6 \mathrm{mg} / \mathrm{m}^{2} /$ day dexamethasone given for 4 weeks. ${ }^{20}$ Cortisol $t_{0}$ levels after chemotherapy in both studies differed significantly from cortisol $t_{0}$ levels before chemotherapy. Our subjects' $t_{0}$ levels were higher than those of Cunha et al ${ }^{20}$ because our subjects were at least 3 years of age, while Cunha et al. ${ }^{20}$ included subjects below the age of 3 years (minimum 1 year of age).

Pre-test $\left(t_{0}\right)$ and post-test $\left(t_{30-60}\right)$ cortisol levels before chemotherapy were significantly different between groups of adrenal insufficiency compared with those without adrenal insufficiency (Table 4). This illustrates that adrenal function or HPA axis was the same in all subjects before chemotherapy. After chemotherapy, pre-test cortisol levels $\left(\mathrm{t}_{0}\right)$ and post-test cortisol levels $\left(\mathrm{t}_{30-60}\right)$ differed significantly between the groups. A similar trend was reported by Mahachoklertwattana et al., ${ }^{16}$ but with a higher median pre-test cortisol $\left(t_{0}\right)$ level than in our subjects.
We observed that adrenal insufficiency tended to occur in children of younger age, including $9 / 10$ of our subjects in the 3-6-year age group. In contrast, Mahachoklertwattana et al. ${ }^{16}$ reported the incidence of adrenal insufficiency occurred more frequently $(67 \%)$ in children aged greater than 5 years. In addition, the adrenal gland recovery time also differed significantly between children aged $\geq 5$ years and those aged $<5$ years. ${ }^{16}$ We found adrenal insufficiency to be more common in male than in female subjects. This observation was not made in other studies, possibly because most of our subjects were boys. Risk group and type of steroid given were not related to adrenal insufficiency, consistent with others' results. ${ }^{16,18}$

Some subjects had non-specific symptoms of steroid withdrawal syndrome such as fatigue, anorexia, nausea, vomiting, abdominal pain, and fever, but these symptoms did not significantly differ between those with and without adrenal insufficiency. Most subjects experienced weight gain, similar to a study by Felner et al. ${ }^{18}$ who reported that central obesity occurred in $8 / 10$ subjects with a mean weight gain of 2.4 (SD 1.7) kg. One subject had stage 1 hypertension after chemotherapy. He also experienced a $4.6 \mathrm{~kg}$ weight gain and visible signs of central obesity, buffalo hump, and moon face. Hypertension is a side effect of glucocorticoid use, with a $45 \%$ incidence reported in children with ALL after completing chemotherapy. This side effect is not related to age, sex, leukocyte count, risk group, body mass index, or serum creatinine level. ${ }^{21}$

One subject who experienced hyperglycemia also had significant weight gain after chemotherapy and showed signs of central obesity, buffalo hump, and moon face. The glucocorticoid dose given to this subject was based on ideal weight, not actual weight. Hyperglycemia may have occurred due to the glucocorticoid effect on carbohydrate and protein metabolism. Glucocorticoids stimulate gluconeogenesis in the liver and increase protein lysis and lipolysis, thereby increasing blood glucose levels. ${ }^{22}$ Baillargeon et al. ${ }^{23}$ reported that the incidence of transient hyperglycemia during the induction phase of chemotherapy in pediatric patients was $11 \%$. Transient hyperglycemia is more likely to occur in older patients (age 13-18 years), with overweight or obese nutritional status and a history of diabetes 
mellitus in the family. ${ }^{23}$ The hyperglycemic boy in our study was 9 years old, obese, and experienced a $3 \mathrm{~kg}$ weight gain after completing the chemotherapy induction phase, but he did not have a family history of diabetes mellitus.

We found that the levels of hemoglobin, leukocytes, and platelets were significantly higher in the group with adrenal insufficiency than in the group without adrenal insufficiency (Table 4). Blood tests were performed 1 week after the last dose of glucocorticoids and in conjunction with the second adrenal function tests. All subjects had anemia, presumably related to the lack of food intake after cessation of glucocorticoids. No subject received blood transfusions within a week prior to blood tests. These findings were not reported in other studies on adrenal function in children with ALL. To date, we have not find a link between adrenal function and changes in hemoglobin, leukocyte, and platelet levels.

This study supports the findings of previous studies that adrenal insufficiency is often found in children with ALL who undergo chemotherapy with glucocorticoids. Our study was conducted in four referral hospitals in Jakarta, so results are representive of the pediatric ALL population in Indonesia. All subjects had normal adrenal function before chemotherapy and served as their own control, therefore, we may exclude any cause for adrenal insufficiency after chemotherapy other than glucocorticoids.

In conclusion, 14/20 children with ALL have adrenal insufficiency after receiving glucocorticoids during the induction phase of chemotherapy, despite a week period of tapering off. There is a statistically significant decrease in median pre-test and post-test cortisol levels before and after chemotherapy in pediatric ALL subjects who complicated the induction phase of chemotherapy. Clinical signs and symptoms, such as fatigue, anorexia, nausea, vomiting, abdominal pain, fever, and weight loss, were not related to adrenal insufficiency.

A large-scale study, with a longer observation period and performance of serial ACTH stimulation tests, is needed to further clarify the mechanism and duration of adrenal insufficiency, determine the magnitude of the problem, and assess the need for glucocorticoid replacement therapy in children with ALL who receive high doses of glucocorticoids during chemotherapy. Physicians who treat pediatric patients with high-dose glucocorticoids for more than 2 weeks need to be aware of the possibility of adrenal insufficiency and test basal cortisol levels in the morning.

\section{References}

1. Feltbower RG, McNally RJ, Kinsey SE, Lewis IJ, Picton SV, Proctor SV, et al. Epidemiology of leukaemia and lymphoma in children and young adults from the north of England, 1990-2002. Eur J Cancer. 2009;45:420-7.

2. Pui $\mathrm{CH}$, Evans WE. Treatment of acute lymphoblastic leukemia. N Engl J Med. 2006;354:166-78.

3. Ribeiro RC, Pui CH. Saving the children-improving childhood cancer treatment in developing countries. N Engl J Med. 2005;352:2158-60.

4. Bonilla M, Gupta S, Vasquez R, Fuentes SL, deReyes G, Ribeiro RC, et al. Predictors of outcome and methodological issues in children with acute lymphoblastic leukaemia in $\mathrm{El}$ Salvador. Eur J Cancer. 2010;46:3280-6.

5. Eden T, Pui CH, Schrappe M, Tognoni G, Masera G, Associazione Italiana di Ematologia ed Oncologia Pediatrica, et al. All children have a right to full access to treatment of cancer. Lancet. 2004;364:1121-2.

6. Howard SC, Pedrosa M, Lins M, Pedrosa A, Pui CH, Ribeiro $\mathrm{RC}$, et al. Establishment of a pediatric oncology program and outcomes of childhood acute lymphoblastic leukemia in a resource-poor area. JAMA. 2004;291:2471-5.

7. Metzger ML, Howard SC, Fu LC, Pena A, Stefan R, Hancock $\mathrm{ML}$, et al. Outcome of childhood acute lymphoblastic leukaemia in resource poor countries. Lancet. 2003;362:706-8.

8. Christensen MS, Heyman M, Mottonen M, Zeller B, Jonmundsson G, Hasle H. Treatment-related death in childhood acute lymphoblastic leukaemia in the Nordic countries: 1992-2001. Br J Haematol. 2005;131:50-8.

9. Rubnitz JE, Lensing S, Zhou Y, Sandlund JT, Razzouk BI, Ribeiro RC, et al. Death during induction therapy and first remission of acute leukemia in childhood: the st. Jude experience. Cancer. 2004;101:1677-84.

10. Saracco P, Bertorello N, Farinasso L, Einaudi S, Barisone E, Altare F, et al. Steroid withdrawal syndrome during steroid tapering in childhood acute lymphoblastic leukemia: a controlled study comparing prednisone versus dexamethasone in induction phase. J Pediatr Hematol Oncol. 2005;27:141-4.

11. Shulman DI, Palmert MR, Kemp SF, Lawson Wilkins Drug and Therapeutics Committee. Adrenal insufficiency: still 
a cause of morbidity and death in childhood. Pediatrics. 2007;119:484-94.

12. Arit W, Allolio B. Adrenal insufficiency. Lancet. 2003;361: 1881-93.

13. Krasner AS. Glucocorticoid-induced adrenal insufficiency. JAMA. 1999;282:671-6.

14. Agwu JC, Spoudeas H, Hindmarsh PC, Pringle PJ, Brook CG. Tests of adrenal insufficiency. Arch Dis Child. 1999;80:330. 3.

15. Einaudi S, Bertorello N, Masera G, Farinasso L, Barisone E, Rizzari C, et al. Adrenal axis function after high-dose steroid therapy for childhood acute lymphoblastic leukemia. Pediatr Blood Cancer. 2008;50:537-41.

16. Mahachoklertwattana P, Vilaiyuk S, Hongeng S, Okascharoen C. Suppression of adrenal function in children with acute lymphoblastic leukemia following induction therapy with corticosteroid and other cytotoxic agents. J Pediatr. 2004;144:73640.

17. Rix M, Birkebaek NH, Rosthoj S, Clausen N. Clinical impact of corticosteroid-induced adrenal suppression during treatment for acute lymphoblastic leukemia in children: a prospective observational study using the low-dose adrenocorticotropin test. J Pediatr. 2005;147:645-50.

18. Felner EI, Thompson MT, Ratiff AF, White PC, Dickson
BA. Time course of recovery of adrenal function in children treated for leukemia. J Pediatr. 2000;137:21-4.

19. Petersen KB, Muller J, Rasmussen M, Schmiegelow K. Impaired adrenal function after glucocorticoid therapy in children with acute lymphoblastic leukemia. Med Pediatr Oncol. 2003;41:110-4.

20. Wheeler K, Chessells JM, Bailey CC, Richards SM. Treatment related deaths during induction and in first remission in acute lymphoblastic leukemia: MRC UKALL X. Arch Dis Child. 1996;74:101-7.

21. Kamdem LK, Hamilton L, Cheng C, Liu W, Yang W, Johnson JA, et al. Genetic predictors of glucocorticoid-induced hypertension in children with acute lymphoblastic leukemia. Pharmacogenet Genomics. 2008;18(6):507-14.

22. Schimmer BP, Parker KL. Adrenocorticotropic hormone: adrenocortical steroids and their synthetic analogs; inhibitors of the synthesis and actions of adrenocortical hormones. In: Hardman JG, Limbird LE, editors. Goodman and Gilman's the pharmacological basis of therapeutics. 10th ed. New York: McGraw-Hill; 2001. p.1649-71.

23. Baillargeon J, Langevin AM, Mullins J, Ferry RJ, DeAngulo G, Thomas PJ, et al. Transient hyperglycemia in Hispanic children with acute lymphoblastic leukemia. Pediatr Blood Cancer. 2005;45:960-3. 